\title{
Mardi Gras: carnaval americano na visão de um brasileiro
}

Fred Góes

A primeira motivação para o desenvolvimento de minha pesquisa sobre o carnaval de Nova Orleans ocorreu ao observar que o texto mais difundido entre nós sobre o Mardi Gras, e provavelmente o único até então, era o capítulo "Carnavais da igualdade e da hierarquia”, do livro Carnavais, malandros $e$ heróis ${ }^{*}$, do professor Roberto DaMatta. Nesse livro, publicado em 1979, DaMatta estabelece relações entre o carnaval brasileiro e o novaorleanense, tendo como referência um artigo do antropólogo americano Munro Edmonson, publicado em 1956. Havia, portanto, um significativo gap histórico a ser observado. Além disso, DaMatta não vivenciara a experiência do Mardi Gras antes da publicação do texto. Decidi, então, vivenciar e pesquisar, in loco, com o mesmo olhar exótico com que os brasilianistas nos observam, como o Mardi Gras se configurava, advertido de que as festas ou celebrações públicas, por estarem vivas, sujeitam-se a mudanças, a transformações, ao longo do tempo. Essa constatação foi indicada, de maneira precisa, por Maria Clementina Pereira Cunha na apresentação da recente coletânea de ensaios de história social da cultura Carnaval e outras $f(r)$ estas, organizada por ela:

Dionísio, Baco, Afrodite e Eros, desde seu antigo Pantheon, assumiram máscaras e rostos muito diferentes ao longo do tempo. Longe de constituírem ocasiões dotadas de alguma espécie de herança imemorial, elas (as festas) têm - mesmo sob uma aparente semelhança - dia, hora, lugar, sujeitos vários e predicados transitórios, significados mutantes e (inevitavelmente) polissêmicos, capazes de expressar a mudança e o movimento."

(DaMatta, Roberto. Carnavavais, malandros e he róis: para uma sociologia do dilema brasileiro. Rio de Janeiro: Zahar Editores 1983).

(Cunha, Maria Clemen tina Pereira. Carnavais e outras $f(r)$ estas: ensaios de história social da cultura. Campinas: Unicamp / Ce

Em "Carnavais da igualdade e da hierarquia", DaMatta toma como parâmetro de comparação o carnaval das krewes, isto é, o carnaval "oficial”, praticado predominantemente pela população branca. Não menciona a existência de um carnaval negro, o dos Mardi Gras Indians (índios do Mardi Gras) ou Black Indians, como os insiders preferem chamá-lo. Isso provavelmente se deveu ao fato de o texto de Edmonson, no 
qual DaMatta se baseou, restringir-se ao lado branco, mais difundido, do Mardi Gras. Nos anos 1950, quando Edmonson escreveu o artigo, os Mardi Gras Indians se apresentavam apenas nas áreas negras da cidade, como ainda acontece hoje, e de forma muito reservada, quase secreta. Além disso, era uma manifestação considerada extremamente violenta, e de fato o era, em razão de desavenças entre as tribos participantes ${ }^{1}$. Somem-se a isso os fatos de que, nesse período, vivia-se um momento de acirrada luta pelos direitos civis e de que Nova Orleans era uma cidade racialmente cindida. A expressão carnavalesca negra não era, portanto, objeto de interesse no universo acadêmico branco, algo não muito diferente do que ocorre contemporaneamente.

Minha segunda motivação surgiu na leitura do artigo "Significando: carnaval afro-creole em New Orleans do século XIX e início do XX”, de Reid Michell, que consta da já mencionada coletânea organizada por Maria Clementina Pereira Cunha. Mais uma vez, deparava-me com um gap histórico e meu interesse recaiu sobre a maneira como o carnaval afro-créole se configuraria no início do século XXI. Vale sublinhar que Nova Orleans é literalmente o que, em inglês, se chama de melting pot (caldeirão de misturas) não só no que se refere à cultura, mas também em seu aspecto geográfico. A cidade, de um lado, nasce e se desenvolve às margens do rio Mississippi, em um local em que este faz uma curva semelhante à lua nascente no hemisfério Norte - daí ser chamada de Crescent city; do outro lado, espalha-se às margens do imenso lago Pontchartrain. Situada entre um lago e um rio, foi construída sobre um pântano que varia entre dois e seis metros abaixo do nível do mar, sendo literalmente, portanto, um caldeirão em região subtropical, uma cidade sujeita todos os anos, entre agosto e novembro, às temporadas de furacões, ou seja, ao risco de desaparecer inundada, como ocorreu recentemente com a passagem do Katrina, que a devastou sobretudo nas áreas habitadas pela população negra.

\footnotetext{
${ }^{1}$ Depois de muitos anos de saídas pacíficas, no ano de 2005, houve desentendimentos entre a polícia e os índios de Downtown. A polícia exigia ter prévio conhecimento do circuito de apresentação das tribos, como ocorre nos desfiles das second lines. Tal gesto,no entanto, romperia uma tradição dessa cultura que é manter em segredo o trajeto, especialmente por questões de segurança, pois os enfrentamentos entre as tribos tinham, no passado, dimensão de guerra campal.
} 
Inserida em uma região, a princípio, inóspita, palco de dezenas de epidemias terríveis, entre as quais a de 1833, na qual um terço da população morreu de febre amarela, Nova Orleans possui diversos cemitérios, muitos deles pontos turísticos, uma vez que, à diferença do que acontece na maior parte dos Estados Unidos, é uma cidade predominantemente católica que esteve sob domínio francês e espanhol por longo período. Nesses cemitérios, há ostensivos mausoléus em mármore e pedras nobres, em que os corpos estão engavetados acima da terra, pois, por ser uma região pantanosa, os corpos enterrados voltam à superfície. Essa é a razão de Nova Orleans ser chamada também de cidade dos mortos, título, aliás, de um belíssimo livro de Joseph Roach*, e de abrigar fortíssima tradição na literatura de mistério e terror, baseada na fabulação oral. Anne Rice, a maior representante da literatura gótica pós-punk, com seus vampiros pós-modernos, só poderia ter surgido em Nova Orleans.

Em 1699, o explorador franco-canadense Pierre Le Moyne, senhor d'Iberville, chegou a aproximadamente setenta milhas de onde se localiza Nova Orleans, mais precisamente, no dia 2 de março. No dia seguinte, conquistou o território, batizandoo de Pointe du Mardi Gras. Era uma terça-feira gorda, Mardi Gras day, mas Nova Orleans só seria fundada alguns anos depois, em 1718.

A expedição de Pierre Le Moyne se estabeleceu na baía de Biloxi, no Mississipi, e em Fort de Louis de la Louisiane (Alabama), nas margens do rio Mobile. A cidade, nomeada a mãe do Mystics - a mais antiga e tradicional agremiação carnavalesca (krewe) novaorleanense -, iniciou sua tradição carnavalesca em 1704, ano em que Nicholas Langois fundou a Société Saint Louis, protótipo das sociedades secretas krewes que mais tarde se constituiriam em Nova Orleans.

A Louisiana, cuja extensão corresponde a um terço do território do país e ia do Canadá ao golfo do México, pertenceu aos franceses e espanhóis até ser definitivamente comprada de Napoleão por Thomas Jefferson em 1803. Nela se desenvolveu uma das mais curiosas sociedades americanas: um caldeirão cultural formado por franceses, espanhóis, acadianos - canadenses da Acádia, hoje Nova Escócia, de origem francesa, expulsos pelos
"(Roach,Joseph. Cities ofthe
dead: circum-atlantic perfor-
mance. New York: Columbia
University Press. 1996) 
ingleses e que acabaram sendo chamados de cajun-, ondurenhos, cubanos, haitianos, caribenhos de toda parte, africanos, negros escravos e livres, chamados gens de couleur. À exceção dos cajun, todos eram chamados de créoles, subdivididos em quadroons, aqueles com um quarto de sangue negro, e octoroons, com um oitavo de sangue negro. Em seguida, chegaram os americanos, que causaram extrema tristeza aos locais. Embora a elite novaorleanense se considere créole, muitas vezes sem sê-lo, ser créole não quer dizer pertencer à elite. $\mathrm{O}$ famoso French Quarter nada tem de french e é sobretudo espanhol, com seus balcões floridos debruçados sobre as ruas e seus pátios internos com fontes, em que se reúnem os privilegiados.

Os novaorleanenses são festeiros, festivos e adoram decorar e expor suas belas casas, especialmente na área originalmente ocupada pelos americanos donos das plantations, o Garden Distric, nos arredores da Saint Charles Avenue, que é cortada pelos trilhos do famoso bonde que inspirou Tennesse Williams. Em outubro, a grande maioria das casas apresenta adornos característicos do Halloween; logo depois, são decoradas para o Thanksgiving em novembro e, imediatamente depois, para o Natal, cuja comemoração vai até 6 de janeiro, quando se inicia a temporada carnavalesca. As casas, então, são enfeitadas para o Mardi Gras nas cores oficiais da festa: roxo, amarelo e verde, que se tornaram as cores oficiais da cidade. Quando não há uma comemoração específica, os moradores hasteiam, na porta das residências, bandeiras com dizeres como joy (felicidade) ou mesmo bandeiras coloridas com desenhos festivos. É muito comum haver árvores enfeitadas com laços de fita nos grandes jardins durante todo o ano. Nova Orleans, enfim, é uma cidade permanentemente fantasiada; quase todo mês, há uma nova máscara. A cidade é continuamente renovada, "carnavalizando" o cotidiano local e proporcionando aos visitantes variadas e renovadas surpresas.

A partir de setembro, há nas comunidades negras, todos os domingos, paradas de second line, assim denominadas porque, na estrutura do desfile, segue-se na segunda linha, estando a primeira reservada ao defunto. As diferentes sociedades de ajuda e prazer (Social \& Pleasure Clubs) desfilam pelas comunidades carregando atrás de si uma multidão de dançarinos vestidos com esmero. Essas agremiações arrecadam fundos para financiar as exéquias dos membros mais pobres da comunidade. Mesmo quando não há funeral, grupos desfilam com 
suas bandas de metais, cantam, dançam e celebram a vida. Tal celebração, em face da morte de um ente querido, tem profunda carga significativa para os descendentes de escravos: a morte não representa perda, mas libertação plena.

O Mardi Gras, que se inicia no dia de Reis, pode durar de 28 a 57 dias, dependendo da data em que cai a quarta-feira de cinzas. Nas primeiras horas da manhã do dia 6 , já se pode encontrar nos supermercados, delicatessens e drugstores o famoso King cake, adaptação novaorleanense do famoso Gallete de roi, típico do norte da França, cuja cobertura açucarada é feita nas cores do Mardi Gras. Comem-se King cakes durante todo o período carnavalesco - em 2004, foram consumidos mais de oito milhões deles -, e dentro deles se encontra o bonequinho da sorte, chamado golden bean ("la fève"). Essa tradição se iniciou em 1870, quando a Krewe de Comus desfilou com um gigantesco King cake, cujo golden bean tornou a moça que o recebeu rainha dessa krewe no ano seguinte.

A origem das comemorações do Mardi Gras é objeto de certa polêmica entre os historiadores. Henri Schindler, apesar de narrá-la em seu livro, confessou-me, em conversa particular, não estar muito seguro de que realmente a história tenha sido a que se segue. Verdadeira ou não, encontrei-a em diferentes textos. Além disso, como se trata de carnaval, de fantasia, creio que uma dose de ficção sempre enriquece determinadas passagens da história, como o sabia Sérgio Buarque de Hollanda, famoso por contar diferentes versões de passagens de sua vida.

Diz-se que, em 1872, um grupo de cidadãos soube que o grão-duque Alexis Romanoff, solteiro e com 22 anos, chegaria a Nova Orleans, vindo de Nova Iorque, onde tinha sido recebido com adulação e pompa. Houve um baile na Academia de Música de Manhattan, cuja decoração tinha pinturas alusivas aos gênios da América e da Rússia. Em Nova Iorque, Aléxis assistira ao musical burlesco Blue beard (Barba azul) e se entusiasmara com uma das músicas cômicas do espetáculo, If ever I cease to love (Se alguma vez eu deixar de amar) e, especialmente, com a atriz e cantora Lydia Thompson, que também era bastante popular em Nova Orleans, onde se apresentaria três meses depois, data correspondente à volta do grão-duque para Rússia. 
A prefeitura de Nova Orleans não programara qualquer recepção oficial, enquanto outras cidades tinham se preparado para receber Alexis. Apenas treze dias antes da chegada do grãoduque, um grupo liderado por Edward C. Hancock, editor do New Orleans Times e figura-chave do Mystic Krewe of Comus, decidiu organizar um desfile de rei, que se tornou a primeira aparição de Rex, o rei do carnaval. Decidiu-se que Rex teria as cores da casa de Romanoff, e que estas se tornariam as cores oficiais do Mardi Gras: green (for faith), verde da esperança, yelllow (for power), amarelo do poder, do dinheiro, e purple (for justice), roxo da justiça.

A canção If ever I cease to love se tornaria o hino do carnival, com seus versos nonsense: "May cows lay eggs and fish get legs/If ever I cease to love (Vacas podem por ovos e peixes criar pernas/ Se algum dia eu deixar de amar) [...] May sheepheads grow on apple trees/If ever I cease to love" (Cabeças de carneiros podem nascer em macieiras/ Se algum dia eu deixar de amar). O grão-duque acabou não ficando com Lydia, e se envolveu com outra atriz, mais moça, Lotta Cabtree, que, antes de se juntar à esquadra real no golfo do México, foi presenteada com uma pulseira de ouro, turquesa, pérolas e diamantes.

O carnaval oficial da cidade é o das krewes, nome das diferentes agremiações ou sociedades que promovem os desfiles e bailes da temporada carnavalesca. Kreweé uma corruptela da palavra crew, que, em inglês, significa tripulação. Esses grupos lembram, de certa maneira, as Grandes Sociedades, os préstitos do antigo carnaval brasileiro, expressão utilizada para designar o desfile de carros alegóricos que percorria as principais avenidas das cidades e que surgiu entre nós em 1885, com o propósito de europeizar o carnaval.

A tradição dos desfiles carnavalescos remonta a década de 1830, em Paris. Consistia em uma evidente demonstração de poder da burguesia nouveau-riche, que se inspirava no corso romano renascentista e "macaqueava" a tradição dos triunfos reais. Tal qual os préstitos no Brasil, as krewes surgiram para reproduzir, em terras americanas, a atmosfera festiva de Paris, Nice e Veneza.

Em Nova Orleans, são sociedades secretas, originalmente formadas por homens brancos. Podem ter três configurações: 
as que desfilam e promovem o grande baile, as que só desfilam e as que só promovem o baile. As últimas são as mais fechadas e, conseqüentemente, as mais seletivas. É nesses bailes que as jovens debutam, isto é, são apresentadas à sociedade. Fazer parte de uma krewe é uma referência social importantíssima na cidade. São inúmeras as krewes e inúmeros os bailes em que os membros estão mascarados, e os convidados homens vestem casaca e as mulheres, vestidos de baile. Seguem-se regras protocolares muito rígidas e todos parecem convencidos de vivenciarem um verdadeiro baile de corte. Essa é a razão de uma das imagens icônicas do Mardi Gras ser uma fotografia de 1950, tornada capa da revista Life, em que se vê o duque de Windsor, o rei da Inglaterra que abdicara ao trono para se casar com uma plebéia americana desquitada, fazendo reverência ao Rex carnavalesco, como se a realeza de verdade houvesse se curvado ao rei de papelão do carnaval.

Os representantes da elite social da cidade procuram deixar claro que há krewes comerciais, das quais pode participar quem se dispuser a pagar pela associação, e as krewes sociais, que só aceitam como membros representantes das famílias tradicionais sulistas. Os membros das krewes se dividem segundo uma rígida estrutura hierárquica. Há o rei, eleito todo ano pelos membros da sociedade, um capitão, também eleito, e oficiais e membros, que ocupam funções como tesoureiro, secretário etc. É nesse universo do carnaval oficial, como bem salientou DaMatta no texto já mencionado, que se pode observar como o carnaval, em vez de subverter, como ocorre entre nós, pode sublinhar ou favorecer a percepção das diferenças, preconceitos e segregações cotidianos. A maioria das krewes é constituída de homens que desfilam sobre os carros, acima da população portanto, e que oferecem prendas, mimos para esta. Em uma sociedade em que tudo se compra e vende, tanto oferecer quanto ganhar assumem carga significativa muito especial. Nada mais magnânimo e confirmador da supremacia do macho branco americano. A primeira krewe apenas de mulheres, chamada Íris, apareceu apenas em 1970. Atualmente, há várias.

Cada krewe costuma desfilar com uma média de 16 floats (carros alegóricos) puxados por tratores - até 1952, eram puxados por cavalos ou burros - e reunir uma média de três mil participantes. Algumas palavras designam elementos fundamentais do universo do Mardi Gras, entre as quais: den, os 
enormes galpões que se espalham pela cidade em que os floats são construídos, e que equivalem aos barracões das escolas de samba; throws, termo geral que designa o que se joga dos carros alegóricos para a população, embora cada uma dessas coisas tenha um nome específico ${ }^{2}$; beads, colares, o mais desejado dos brindes - as árvores da Saint Charles Avenue, no trajeto por onde passa o desfile, ficam carregadas de colares que os participantes não conseguem fazer chegar à população; blooms, moedas cunhadas por cada krewe, e que foram introduzidas pela Krewe de Rex em 1960 - de um lado, há a insígnia da krewe; do outro, o tema de cada desfile; fambleau, grande prancha de metal em que há candeeiros de querosene, carregadas por negros, pobres em geral - trata-se de uma atividade perigosíssima, sendo costume da audiência atirar moedas para esses negros, que quase nunca conseguem pegá-las, pois podem se queimar. ${ }^{3}$

O boeuf gras (boi gordo), referência à abundância da carne, ao excesso característico do carnaval, é um elemento tradicional do carnaval parisiense do século XIX que foi apropriado pelo Mardi Gras. Em muitos eventos populares parisienses, havia uma parada que se sobressaía em originalidade e se configurava como uma expressão à qual se poderia atribuir traços mitológicos da Antigüidade, ligados à reinvenção de uma origem milenar baseada em práticas culturais imemoriais não registradas pela história: o desfile do Boi Gordo. Tal desfile seria uma expressão exemplar para a burguesia justificar a celebração carnavalesca como forma culturalmente alicerçada, tendo sido promovida pelos açougueiros parisienses. Consistia em um desfile cuja figura central era um boi cevado enfeitado com guizos, fitas, uma coleira de flores e outros

${ }^{2}$ Há, entre os throws, copos, bonecos, rosas de plástico, calcinhas, pandeiros, chapéus e bichos de pelúcia. Um dos throws mais especiais, e que adquiriu a dimensão de honraria para quem o recebe, é o coco oferecido pela krewe Zulu, originalmente de negros pintados de negro, que parodiavam o carnaval oficial, e que hoje é predominantemente de brancos pintados de negros.

${ }^{3}$ Os flambeau são uma tradição do século XIX, pois eram eles que iluminavam os floats. Diz-se que, ainda no início do século XX, eram os presidiários que os carregavam. Hoje, os presidiários limpam as ruas depois dos desfiles. De modo semelhante, no desfile das Grandes Sociedades no Brasil do século XIX, os carros alegóricos eram iluminados por um grupo de homens que carregavam tochas, conhecidas como fogo de bengala. 
acessórios, e montado por um menino vestido de cupido, precedido por foliões fantasiados de deuses do Olimpo. ${ }^{4}$

O boi gordo vivo fez parte do desfile da krewe de Rex até 1909. Reapareceu, cinqüenta anos depois, sobre um carro, em papel machê, tornando-se um dos símbolos mais representativos do carnaval da cidade. Da mesma forma que na França do século XIX, foi investido de uma tradição "inventada". Ouvi de um convicto especialista em Mardi Gras que o boeuf gras era uma reminiscência das celebrações populares medievais, que, por sua vez, aludiam ao bezerro de ouro pagão citado no Velho Testamento, comprovando que o universo carnavalesco é uma fonte abundante de material ficcional para a realização de fantasias, no sentido mais amplo possível da palavra.

O governo não financia o carnaval. O município responde pela segurança e pela assistência sanitária, mas não concede verba oficial. As krewes são autônomas, os sócios pagam o desfile e os bailes, se os promoverem. Há krewes de todos os níveis sociais, desde as de bairros com duas dezenas de membros às grandes, com centenas ou milhares deles. As paradas percorrem em média sessenta milhas. Em 2004, desfilaram 73 agremiações. Muitas delas surgem e desaparecem, bem como têm nomes mitológicos: Orfeu, Dionísio, Apolo, Prometeu, Osíris, Isis e mesmo Krewe de Oxum.

As bandas que acompanham os desfiles são de escolas secundárias, cujos alunos se vestem com uniformes de gênero militar e levam à frente moças com suas balizas. Eexecutam dobrados militares.

Uma grande krewe, a Krewe du Vieux, é a única que mantém o velho espírito crítico do carnaval, desfila a pé no French Quarter e abre a temporada dos desfiles. Seus carros são pequenos e puxados a burro. Os componentes se dividem em grupos que se responsabilizam pelas diversas atividades, como a confecção das fantasias e dos carros, e a compra dos beads. É constituída por 17 subkrewes e sempre trata de um tema polêmico que satiriza a ordem constituída.

$\mathrm{O}$ carro da Krewe of underwear - underwear é a ceroula inteiriça vermelha usada pelos bombeiros no inverno -, o grupo a que me associei, era um templo egípcio, o templo da

${ }^{4}$ A referência aos deuses mitológicos estabeleceria a relação entre a celebração francesa e uma possível origem histórica investida de uma faceta tradicional. 
imoralidade, em que havia uma múmia, sentada em um barco de Osíris, com um grande cheque na mão, no qual se lia: $\$$ PHANTON EMPLOYER PAYCHECK (cheque de pagamento de funcionário fantasma). Seu tema central era: The quest for immorality [A busca da imoralidade], uma paródia à enorme exposição sobre o Antigo Egito apresentada no New Orleans Museum of Art (NOMA), cujo título era The quest for immortality [A busca da imortalidade].

A estética de todos os carros era propositadamente "bagaceira", ainda que se encontrassem alguns formidavelmente confeccionados. Uma das características dos americanos é a capacidade de realizar com grande habilidade trabalhos manuais. Como os serviços contratados são muito caros, eles próprios acabam lidando com os problemas domésticos. Desde cedo, fazem trabalhos de marcenaria, hidráulica etc. Em situações como o carnaval, essa característica se torna visível. Um arquiteto desenha os floats e, auxiliado por um outro profissional, como um engenheiro de computação da Nasa, transforma tubos de papelão e isopor recobertos de papel machê em colunas egípcias. Em um dos carros, trabalhavam duas mulheres, uma comerciante e a outra enfermeira, que me disseram que o trabalho no galpão, isto é, a preparação do carnaval e a confecção dos carros, fazia com que sentissem ainda jovens.

Foi trabalhando em um desses galpões em Nova Orleans que tive a clara percepção de que o carnaval definitivamente possibilita o mergulho no lado de lá, no outro lado, na máscara, na folia, cuja etimologia se refere a folie, loucura. Talvez por isso, em inglês, as trupes itinerantes, os freak shows e parques de diversão, cuja vida é mambembar, sejam chamados de carnival. Carnival, ou carnaval, é essa oportunidade de "pôr para fora”, de dançar com os elefantes, libertar as feras que temos em nosso circo imaginário. Carnaval é viajar com o seu circo interior, dar a ele espaço na vida.

Em Nova Orleans, paralelamente ao carnaval das krewes ou carnaval oficial branco, há um carnaval negro cujo ponto alto são homens negros vestidos de índios. Algumas questões fundamentais, para as quais temos buscado resposta, referem-se ao que leva os negros, nas Américas, a se vestirem de índios no carnaval. Isso ocorreria como uma forma de reação à expressão oficial e branca ou teria como referência a busca de uma identidade americana, isto é, uma forma de representar 
simbolicamente o pertencimento ao território americano? Referenciar por meio da indumentária os donos da terra americana não equivaleria a tomar de empréstimo o culto aos ancestrais e entidades africanas? Haveria algum tipo de identificação entre a idéia de liberdade do silvícola e a de libertação da escravatura, como ocorre, por exemplo, nas comemorações cívicas da Independência, na Bahia, no dia 2 de julho, em que as homenagens ao caboclo são o clímax da festa? Essa hipótese de pertencimento e identificação não é aventada por David Elliot Draper, um dos estudiosos do assunto, para quem as fantasias dos Mardi Gras Indians (índios do Mardi Gras) teriam como fonte de inspiração o Wild West Show (Show do Oeste selvagem), de Buffalo Bill, que se apresentou em Nova Orleans em 1885, durante a Exposição Mundial da Indústria do Algodão, uma vez que a classe trabalhadora negra que freqüentava os shows se identificava com os índios massacrados no espetáculo.

De todo modo, as questões que envolvem a cultura dos índios do Mardi Gras são extremamente complexas. Aqui, limito-me a observar, de forma esquemática, os trajes que, a princípio, pareceram-me assemelhar-se às fantasias dos destaques das escolas de samba, mas que, na verdade, são bastante singulares. Em primeiro lugar, essas roupas não são confeccionadas para produzir um efeito para quem as vê à distância, como nas escolas de samba, nas quais os destaques desfilam em carros alegóricos e seus esplendores fixos são idealizados para causar efeito. Os trajes dos índios do Mardi Gras se destacam pelas minúcias, pelos detalhes de cenas bordadas em minúsculas miçangas. Além disso, os índios do Mardi Gras não desfilam em carros e não se apresentam para multidões. São uma manifestação do proletariado negro, da classe trabalhadora, das comunidades pobres que, no dia do Mardi Gras, saem de seus bairros e se dirigem para a Claiborne Avenue.

Em meados dos anos 1960, foi construído sobre essa avenida um grande viaduto, que desfigurou o local que era uma área de grande efervescência da cultura negra. Em sinal de protesto, os índios se reúnem debaixo do viaduto, local em que foram pintados grandes painéis com imagens de Mardi Gras Indians, do mesmo modo que foram pintadas, nas colunas das extremidades do viaduto, árvores recordando os típicos living oaks do pântano que havia no local, onde hoje só há concreto. 
Eles desfilam na comunidade e para comunidade, fora do circuito oficial. Estão fora, portanto, do circuito turístico. Os chefes saem para mostrar sua "pretty" para os vizinhos. Celebrar sua cultura sem se preocuparem com consumo, beads ou propaganda, configurando-se como uma ostensiva afirmação cultural negra. Apenas em duas ocasiões saem, pela manhã, da área em que vivem: na terça-feira gorda, ou Mardi Gras Day, e no Big Sunday, o domingo mais próximo do dia 19 de março, dia de São José. A importância dessa data se deve ao sincretismo da grande festa siciliana e sobretudo ao fato de ser o dia que, no Caribe, celebra-se Legba, o guardião das encruzilhadas e espírito da comunicação em todas as esferas da comunidade vodu.

Cada indivíduo desempenha papel específico na tribo. As roupas de um big chief (grande chefe) custam de 35 a cinqüenta mil dólares e jamais são repetidas. A estrutura organizacional dos índios segue uma hierarquia rígida. Há o big chief, o second chief, a queen, o wild man, o spy boy e o flag man. Também há uma hierarquia familiar. Por exemplo, Brian Nelson, da tribo Guardians of the Flame, é um jovem big chief que herdou o posto de seu avô.

O espião sai dois quarteirões à frente do grande chefe para saber se sua tribo pode passar sem perigo; o porta-bandeira, o pajé, a rainha, as princesas e a figura máxima, o big chief, ocupam os principais postos da gang. Cada um apresenta um gestual, uma dança e uma fantasia que os identificam. Para merecer o cargo de big chief, o indivíduo precisa preencher uma série de requisitos: ser um membro ativo e representativo de sua comunidade, ser um chefe de família com qualidades destacáveis, ser bom cantor e conhecer o repertório tradicional, e ser habilidoso e criativo para conceber e confeccionar, a cada ano, um novo traje que deverá ser inteiramente bordado por ele próprio. As roupas são narrativas e, quando as tribos se encontram, os big chiefs devem ser capazes de ler as roupas uns dos outros. Tootie Montana ${ }^{5}$, o mais velho dos big chiefs e um dos últimos falantes da língua créole, revolucionou esse traje ao introduzir o saber de sua profissão cotidiana. Gesseiro e autoridade no restauro de sancas, conferiu tridimensionalidade às roupas, ao bordar volumes que se projetam no oceano de plumas.

\footnotetext{
${ }^{5}$ Tootie se tornou uma legenda da cultura dos índios do Mardi Gras. Após um infarto, faleceu em abril de 2005, em pleno tribunal, enquanto defendia a posição das tribos de não comunicarem previamente seus trajetos à polícia. Ele saiu no carnaval pela última vez em 2004.
} 
Até meados do século XX os encontros entre chefes, como observado, redundavam em verdadeiros confrontos tribais, nos quais muita gente se feria ou morria. Hoje, a guerra é pela beleza. Busca-se saber quem é o mais belo big chief de cada ano. A roupa varia de acordo com a área - cidade alta, baixa ou centro -, havendo trajes inspirados nos índios das planícies ou nas culturas africanas.

Sempre há em torno dos chefes crianças, mulheres e uma banda de percussão com vários instrumentos improvisados (latas, garrafas etc.). As músicas demonstram a diversidade das sonoridades negras da área do Golfo, embora se repitam tanto nos versos quanto na levada rítmica, cuja origem é a bamboula, palavra derivada de bambu, pois o tambor menor, executado na dança, era freqüentemente confeccionado de bambu duro.

Em 2004, contamos 14 tribos de Mardi Gras Indians, entre as quais algumas já tradicionais, como Guardians of the Flame (big chief Brian Nelson), Congo Nation (big chief Donald Harrison Jr.), Seminoles (big chief Joseph "Joe Pete" Adams), White Cloud Hunters (big chiefCharles Taylor), White Eagles (big chief Felton Brown), Golden Eagles (big chief Joseph Pierre (Monk) Boudreaux), Yellow Pocahontas (big chief Allison Tootie Montana, chief of the chiefs), Wild Magnolias (big chief Bo Dollis) e Wild Tchoupitoulas (big chief (o velho) George Landry, conhecido como big chief Jolly). Os ensaios dos índios acontecem em botequins fechados das comunidades negras e não estão abertos a qualquer desavisado. O recinto é dividido por uma corda e a practice se inicia com uma oração do grupo em roda e, depois, o canto do repertório tradicional, cuja seqüência obedece a uma lógica especial. Começam cantando My indian is red e, a partir daí, cada canto atende a uma determinada situação. A visita de um chefe a uma outra tribo implica, após uma cerimônia e danças que mais parecem brigas, nas quais há insultos, o canto de The indians are coming. Assim, o acesso a esse universo, ou seja, ter vivenciado o carnaval tanto dos brancos quanto dos negros nos Estados Unidos, foi uma experiência extremamente enriquecedora. Com o Katrina, provavelmente muito do que foi aqui exposto leve algum tempo para se recompor. Não creio, no entanto, que essa tradição desapareça, afinal a cultura negra de Nova Orleans parece ser mais forte que o furacão. 


\section{Fred Góes}

Formado em Letras, com mestrado em Comunicação e Cultura pela Escola de Comunicação da UFRJ. Doutor em Teoria da Literatura pela Faculdade de Letras da UFRJ, onde ensina no Departamento de Ciência da Literatura. Entre 2003 e 2004, desenvolveu pesquisa de pós-Doutoramento junto ao Stone Center for Latin American Studies da Tulane University, em Nova Orleans, Estados Unidos, com bolsa da Fundação Rockefeller. Paralelamente à atividade acadêmica, é pesquisador de música popular, compositor/letrista e ensaísta crítico. Tem oito livros publicados nas áreas de literatura e música popular.

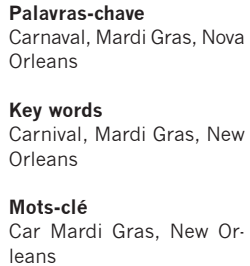

Aprovado em 20/11/2005

\section{Resumo}

O presente artigo resume os aspectos principais da pesquisa sobre o Mardi Gras de Nova Orleans, desenvolvida entre os anos de 2003 e 2004 junto à Universidade de Tulane, com destaque para o fato de haver duas formas distintas de expressão carnavalesca na cidade: a branca "oficial” e a negra "não-oficial”.

\begin{abstract}
The present article abbreviates the main aspects of my researche on New Orleans' Mardi Gras at Tulane University during the years of 2003 and 2004. It emphasizes the presence of two different forms of celebration in the city: the white and "official" one, and the black “non-official”.
\end{abstract}

\section{Résumé}

Cet article résume les aspects les plus importants de la recherche sur le Mardi Gras de Nouvelle Orléans que j’ai développée en 2003-2004 auprès de l'Université de Tulane. On y met en relief la présence de deux formes distinctes d'expression carnavalesque: celle des blancs, "officielle", et celle des noirs, "non-officielle". 